\title{
O olhar do adolescente sobre a liberdade na escola: um estudo fenomenológico-compreensivo
}

\author{
The adolescent's point of view about freedom in school \\ context: \\ a phenomelogical-comprehensive study
}

\author{
Rita de Cássia Vieira* \\ Universidade Federal de Minas Gerais- UFMG, Belo Horizonte, Minas Gerais, Brasil
}

\begin{abstract}
RESUMO
Este trabalho focaliza as experiências da liberdade de adolescentes no contexto escolar. Foram realizadas entrevistas individuais semi-estruturadas com doze alunos. Os conteúdos expressos foram analisados com base numa estrutura de etapas proposta por Amatuzzi e concluiu-se que um contexto escolar mais liberal pode favorecer no processo de amadurecimento do adolescente, orientando-o no aprendizado da responsabilidade e da autonomia. A adolescência foi significada pelos entrevistados como uma complicada e confusa transição do status de criança para o de adulto. Estes adolescentes, ao viverem sua liberdade, entendem que ela comporta em si um caráter de contenção, de restrição e o fazem com base numa decisão que sabidamente terá ressonâncias no seu futuro; nesse processo decisório, onde a figura do outro é significativamente importante, predominam características como irreflexão e impulsividade.
\end{abstract}

Palavras-chave: Adolescência, Escola, Liberdade, Fenomenologia.

\begin{abstract}
This article focuses on the adolescent's freedom experiences in a school context. Semi-structured interviews were conducted and twelve students were interviewed. A phenomenological analysis approach based on the model proposed by Mauro M. Amatuzzi was used to interpreted data collected, which concluded that a liberal school context could be favourable to the adolescent's maturation process and lead them to the development of responsibility and autonomy. Adolescence represents a complex and confused transition between childhood and adulthood. These adolescents, whilst experiencing their freedom, understand that it has characteristic traits of restriction and they know that their decisions will have an impact on their futures. In this decision process, the other is meaningful and characteristics like rashness and impulsivity use to prevail.
\end{abstract}

Keywords: Adolescence, School, Freedom, Phenomenology.

\section{Liberdade e adolescência no contexto escolar}

Dada a necessidade de conhecer e explorar o novo, o desejo de desfrutar a liberdade de forma mais ampla é uma constante na 
adolescência. Com isso, a temática da liberdade encontra-se intimamente relacionada com esse período da vida humana e constitui-se um importante eixo de investigação para os interessados nos estudos sobre adolescência. Contudo, verifica-se que investigações sobre o tema da liberdade na adolescência são insuficientes e tal constatação fica ainda mais evidente quando esse assunto é examinado no contexto escolar, visto que não existem pesquisas que privilegiem a ótica adolescente $e$, mais especificamente, que sejam fundamentadas num enfoque psicossocial. Os poucos estudos encontrados, além de não se centrarem no momento adolescente, ou se fundamentam em um enfoque estritamente educacional (COELHO SOBRINHO, 1986; GALLO, 1993; GOMES, 1994) ou, ainda, se localizam em outros campos do saber, como por exemplo, o da enfermagem (WESTERA; BENNETT, 1994) e da antropologia (CORREA, 1982).

No estudo das teorias psicológicas sobre a adolescência, observa-se a existência de uma visão marcadamente naturalista, que universaliza esse período do desenvolvimento humano e o caracteriza como um momento de instabilidade, crise, tensões e conflitos internos e sociais. Contrapondo-se a esse ponto de vista estabelecido por Stanley Hall no início do século XIX, concepções da adolescência fundamentadas na psicologia cultural a apresentam como um período passível de ser compreendido apenas a partir de sua inserção na totalidade do contexto histórico-cultural onde o mesmo se insere (MUUSS, 1976; ERIKSON, 1972, 1998; ABERASTURY; KNOBEL, 1980, 1981; MARTINS; TRINDADE; ALMEIDA, 2003; BOCK, 2004).

O conceito de liberdade, por inúmeras razões, dentre as quais se destacam a complexidade e a abrangência, insere-se na categoria daqueles de difícil apreensão. Acrescente-se a esse quadro uma dimensão que Marques (2000) vai chamar de pré-teórica, configurada por todos aquelas concordâncias que as pessoas têm em relação ao conceito no seu cotidiano. Tendo em vista que diferentes culturas, em diferentes momentos, produzem diferentes concepções de liberdade, ao longo dos tempos, uma pluralidade de abordagens foi-se conformando e tornando essa noção cada vez mais densa. A despeito desse intricado quadro, observa-se que as teorizações propostas pelos pensadores modernos da liberdade contêm um eixo comum, que se encontra representado pela autonomia do homem frente à sua existência, ou seja, pelo seu poder de escolha, pelo seu posicionamento frente às inúmeras opções que Ihe são apresentadas durante a sua existência. Essa concepção de liberdade surge para a humanidade, portanto, como algo que tentará dar conta do homem na sua relação consigo mesmo, com os outros, e com as normas e leis também por ele produzidas. Nas sociedades modernas, podemos dizer que essa questão se transforma num verdadeiro enigma, uma vez que o sujeito encontra-se atualmente diante de um sem-número 
de possibilidades em vários aspectos de sua vida, tendo que, a todo momento, se posicionar por aquela supostamente ideal e que venha a atender suas expectativas de sujeito de sonhos e desejos (ZAVALLONI, 1968; RABUSKE, 1986, 2001; GEYMONAT, 1991; GUSDORF, 1979; RENAUT, 1998; RICOEUR, 1999).

Aproximando a discussão do âmbito da educação, nota-se que dois importantes pressupostos são fundamentais ao se examinar a noção de liberdade no contexto das tendências educacionais brasileiras. Um deles é a reafirmação de que as práticas pedagógicas refletem, explícita ou implicitamente, uma concepção de liberdade que são conseqüência da visão de homem que cada uma delas procura transmitir e formar. Acresce-se a isso que essa concepção, ao ser compartilhada por um determinado grupo social no seu dia-a-dia, se constitui num reflexo vivo de condicionantes históricos, políticos, econômicos e socioculturais vividos por esse mesmo grupo e, sendo assim, a liberdade, além de ser entendida como uma manifestação individual, deve também ser compreendida numa dimensão que inclua o aspecto da coletividade. Nessa perspectiva, a legislação educacional vigente no país no período compreendido entre 1930 e 1990, vai gradualmente conformando uma concepção de liberdade enquanto característica natural e comum a todos os homens, e, ainda, garantida legalmente, já que "todos os homens são livres e iguais perante a lei" (BERTAN, 1994). Essa concepção de liberdade, conseqüência do pensamento liberal, defende a liberdade e os interesses individuais, fomentando o individualismo nas sociedades baseadas no modo de produção capitalista e alçando-o à condição de paradigma na modernidade (RENAUT, 1998). Isso, sem dúvida, tem repercussões de peso nos contextos educativos/escolares e, mais ainda, na forma como os sujeitos que se encontram nesses espaços vivem a sua liberdade e direcionam suas ações.

Questões cruciais se impõem para educadores, como por exemplo, a necessidade de orientar 0 adolescente na articulação de suas demandas individuais por liberdade com as inúmeras possibilidades, atrativos, exigências e solicitações da vida moderna. Sendo a escola uma instituição-chave e com participação significativa no processo de construção identitária em curso na adolescência, os processos educativos que aí se desenrolam podem efetivamente contribuir - ou não - para a formação de sujeitos mais - ou menos - capazes de lidar de forma crítica e responsável com a liberdade nesse espaço e fora dele. Tendo em vista a multiplicidade de classificações no que diz respeito às tendências pedagógicas na cena educacional brasileira, optou-se no presente estudo por um recorte delimitador que possibilitasse apresentar com mais detalhamento duas fundamentais concepções em educação, que nos permitissem compreender e situar a escola estudada, quais sejam a tradicional e a liberal, centrando a atenção no movimento escolanovista. 
A educação liberal sustenta-se em referenciais importantes advindos do pensamento rousseauniano, tais como o respeito ao indivíduo e o culto à liberdade no sentido de se garantir o desenvolvimento integral da pessoa em todas as suas potencialidades, como também a idéia acerca da necessidade de se criar um novo homem para uma nova sociedade. Entretanto, à idéia colocada por Rousseau de que a liberdade faz parte do homem, de que é intrínseca a ele, a perspectiva liberal acrescenta a noção de liberdade conquistada e construída socialmente. Seria, portanto, objetivo dessa pedagogia, criar um novo homem, assim como uma nova sociedade, com base na afirmação do ideal de liberdade. Ancorado nessa noção proposta pela pedagogia liberal e, ainda, no pragmatismo de Dewey (2), é que surge no Brasil, no início deste século, o movimento escolanovista, que vem advogar a causa do tratamento diferenciado para o aluno com base na ênfase das diferenças individuais. Sob a abordagem da escola nova, modificam-se as tradicionais relações existentes entre professor/aluno/escola: o professor deixa de ser aquele que ensina e dono do saber, e passa a ser um facilitador do processo educacional, aquele que ajuda o aluno a aprender. O aluno, por sua vez, é visto como o centro, um sujeito único, diferenciado e que vê serem valorizados seus interesses, sua capacidade de observar, de pensar, criticar e sintetizar. A escola modifica o seu aspecto: de disciplinada e sombria, passa a ser um ambiente alegre e movimentado, uma comunidade livre. Incentivando, valorizando e, até mesmo, oportunizando a liberdade dentro do seu contexto, essa escola passa, assim, a se posicionar como democrática, estimulando o aluno a construir sua própria liberdade: centrada na ação, na atividade por meio da experiência, a escola torna-se um espaço onde o educando é convidado a ser livre, a exprimir-se livremente, numa liberdade "vigiada" (CHARLOT, 1983, p. 160).

Nessa perspectiva, o estudo buscou conhecer e analisar as concepções da liberdade de adolescentes/alunos de uma escola pública, a partir da identificação e análise de possíveis impactos desse contexto na vivência da liberdade dos entrevistados.

O referencial teórico-metodológico utilizado buscou articular algumas conceituações de liberdade com alguns conceitos centrais para a perspectiva fenomenológica em psicologia - em especial o conceito de experiência -, discutindo-os numa aproximação com alguns dos estudos clássicos sobre a adolescência e, ainda, inserindo todas essas temáticas no debate educacional contemporâneo.

\section{Método}

Neste estudo, optou-se pela pesquisa de orientação fenomenológica, entendendo-se que o método fenomenológico de fazer pesquisa não 
se constitui num método explicativo e sim num método de descrição, de compreensão, onde se procura captar a intencionalidade do objeto pesquisado. A perspectiva aqui é de que a realidade sempre é percebida com um significado que lhe é atribuído - o vivido - e, sendo assim, a pesquisa fenomenológica vai tentar penetrar nesse significado, buscando desvelar aquilo que se encontra oculto por detrás dos dados levantados numa investigação, aquilo que não aparece imediatamente, ou seja, buscando ir além do nível explicativo.

A centralidade dessa postura - influenciada pelas proposições de Husserl (1897/2002) - reside na busca de se captar a intencionalidade, o significado atribuído pelo sujeito a um determinado objeto, elucidando as relações entre a experiência direta vivida por esse sujeito e o significado que essa experiência tem para o mesmo. Tal experiência, além de possuir um componente perceptivo e um afetivo, comporta ainda uma terceira dimensão, a intelectiva, caracterizada pela elaboração em si, pela crítica, pelo juízo emitido a partir de uma determinada vivência. Esse aspecto é de fundamental relevância ao se observar que o conhecimento de algo que nos é externo implica no autoconhecimento, ou seja, o objeto da experiência não é somente o fenômeno, mas também o próprio sujeito, que emerge da experiência e também está presente nela, ou seja, não existe apenas o sujeito da experiência, mas um ser que, ao conhecer, também se revela na experiência (GIOVANETTI, 1999, 2000; MAFHOUD, 1999; WOJ TYLA, 1982).

Partindo dessas orientações centrais da fenomenologia, Amatuzzi (1996, 2001a, 2001b, 2009), sugere um formato de pesquisa fenomenológica que consiste numa análise psicológica de vivências, num estudo de experiências específicas e situadas. Na proposição desse autor, existe uma estrutura de passos a serem seguidos no desenvolvimento de uma pesquisa psicológica fenomenologicamente conduzida. E foram essas etapas (AMATUZZI, 1996, 2009) que deram suporte à pesquisa aqui apresentada. Em resumo, parte-se de uma delimitação precisa do objeto de estudo para um encontro com o fenômeno e sua alteridade em termos concretos, passando por momentos onde os depoimentos são lidos, revistos, analisados - em partes e no todo - e, finalmente, articulados e interpretados. Nesse percurso, há uma busca incessante para compreender a totalidade do vivido, com vistas a se chegar a uma descrição consistente e aprofundada do fenômeno estudado.

\section{Local de realização da pesquisa}

Explícita ou implicitamente, as práticas pedagógicas refletem uma concepção de liberdade que é conseqüência da visão de homem que 
cada uma delas procura transmitir e formar (BERTAN, 1994; WEISZ; SANCHEZ, 2002). Nessa perspectiva, a escolha do local de desenvolvimento da pesquisa recaiu no Colégio Técnico da Universidade Federal de Minas Gerais (Coltec), considerada nesse estudo como instituição-representativa de um contexto escolar democrático/liberal. Abrigando um corpo discente na faixa etária compreendida entre 14 e 18 anos de idade e tendo como uma de suas singularidades o fato de se situar dentro de um campus universitário, essa escola tradicionalmente orienta seus processos educacionais fundamentada num modelo de gestão escolar democrática. Com isso, antecedendo as decisões, as condutas educativas/escolares são tratadas e encaminhadas de forma dialógica com alunos, pais/familiares, professores, direção, técnicos educacionais e funcionários envolvidos, buscando-se soluções que atendam aos interesses de todas as partes e que não se afastem da proposta educacional da escola.

\section{Participantes}

$\mathrm{Na}$ composição do grupo que seria objeto de análise nessa investigação, foi inicialmente determinado um primeiro critério: o do interesse pessoal dos sujeitos, que seriam estudados em dar os seus depoimentos sobre o tema examinado. Dessa forma, nos contatos com os alunos em suas respectivas salas de aula, realizou-se uma breve explanação sobre o processo de pesquisa em desenvolvimento, reafirmando a mobilização causada pela temática na pesquisadora e solicitando a colaboração dos interessados. Entre aqueles que atenderam à solicitação, foram selecionados 12 (doze) alunos de ambos os sexos, ficando assim constituído o grupo investigado: 04 (quatro) alunos da $1^{\text {a }}$. série, 04 (quatro) da $2^{a}$. e 04 (quatro) da $3^{a}$. série. Essa formação do grupo por séries teve como pressuposto básico favorecer a investigação de três importantes momentos vividos pelo adolescente no contexto estudado: o momento de ingresso na escola, o de saída, e, ainda, um momento intermediário. Acrescente-se, finalmente, que os sujeitos são chamados por Amatuzzi (2003) de colaboradores, pois ele entende que a pesquisa fenomenológica não lida com pessoas que fornecem informações, mas colaboradores que, juntamente com o pesquisador, tratam do assunto. O colaborador é quem melhor sabe de sua experiência, ao passo que o pesquisador se propõe a aprender com quem já vivenciou ou vivencia a experiência sobre a qual ele busca conhecer.

\section{Procedimentos de coleta e análise de dados}


Devido ao caráter interativo e relativa flexibilidade de percurso, optou-se na coleta de dados pela realização de entrevistas individuais semiestruturadas, as quais foram gravadas e transcritas literalmente. Tendo em vista os objetivos da pesquisa, foi utilizado um roteiro privilegiando as seguintes temáticas: 1 . o que é adolescência e o que é ser adolescente; 2 . o que é liberdade para o adolescente; 3. o processo decisório; 4. a liberdade na adolescência e no contexto escolar (englobando os subtemas: a liberdade na adolescência; a liberdade na escola; família $x$ escola $x$ liberdade; impactos no confronto com um regime disciplinar liberal/democrático; usos da liberdade na escola e na vida em geral). Durante os depoimentos, os temas foram encaminhados na direção de uma escuta que favorecesse a pesquisadora captar e descrever a essência presente nas experiências vividas (AMATUZZI, 1996, 2001a, 2001b, 2009; HUSSERL, 1897, 2002).

Após inúmeras leituras, a análise do corpus levou ao agrupamento dos conteúdos expressos em quatro grupos temáticos/categorias, que foram organizados como a seguir: liberdade (aqui, além de todos os conteúdos relacionados diretamente com este tema, foi incluída também a temática relativa ao processo decisório - entendida como elemento fundamental para a compreensão da liberdade - e, é claro, o próprio conceito de liberdade; liberdade e adolescência (conteúdos relativos à vivência da liberdade no momento da adolescência e, ainda, o próprio conceito de adolescência); liberdade na escola (conteúdos vinculados à vivência da liberdade no contexto escolar); limites e possibilidades na vivência da liberdade (conteúdos relacionados às dificuldades, conflitos, desafios e facilitações encontradas pelo adolescente para viver a sua liberdade). Numa etapa posterior, e considerando também a particularidade dos significados aflorados em cada depoimento, foi identificada uma estrutura geral desses significados, que será explicitada e discutida adiante.

\section{Resultado e discussão}

Organizadas e articuladas, as vivências da liberdade no contexto da escola em estudo, descritas pelos adolescentes entrevistados, compuseram uma estrutura ativa e integrada, que se inter-relaciona de forma dinâmica, processual e não-hierarquizada: 

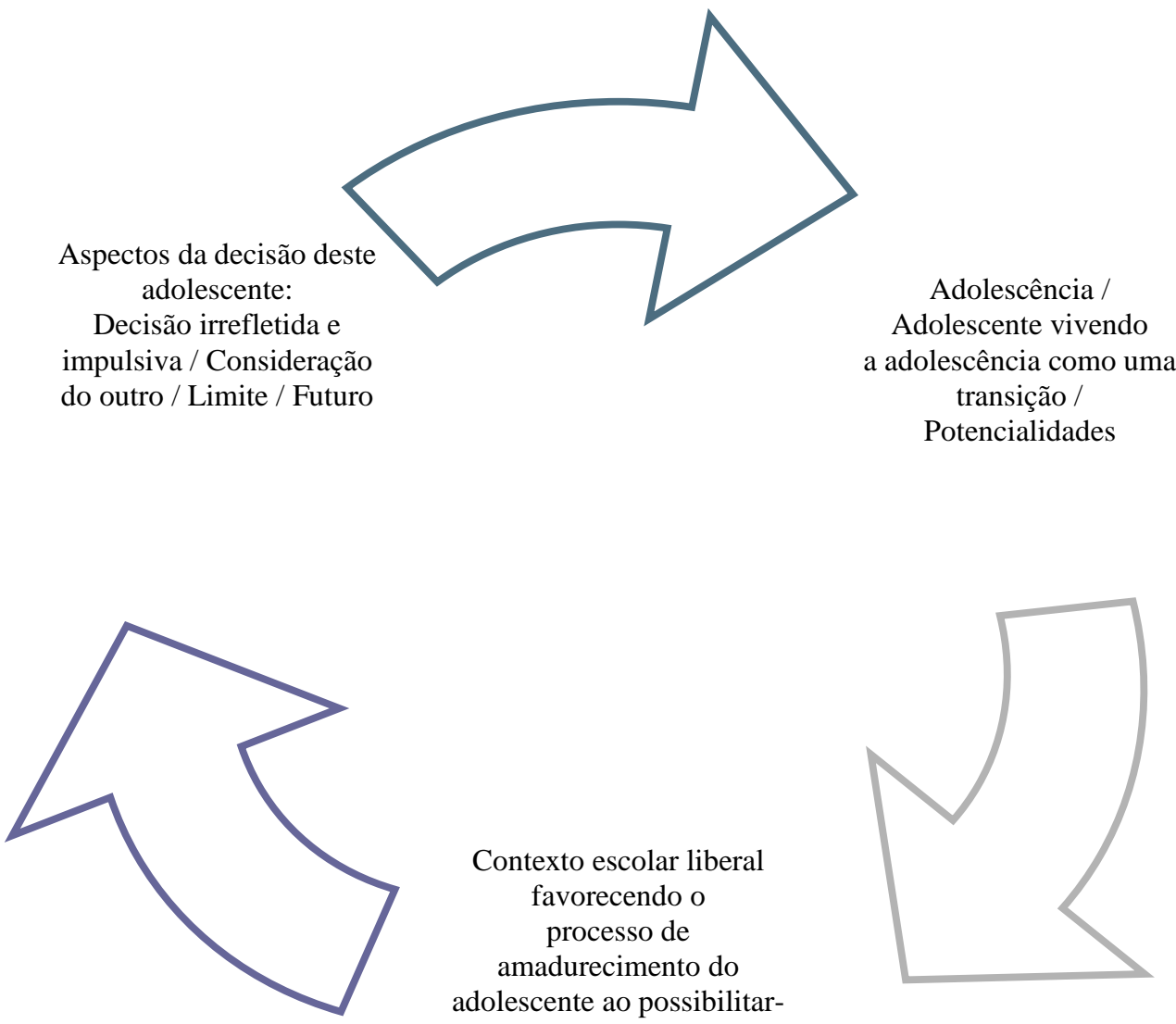

Contexto escolar liberal favorecendo o processo de amadurecimento do adolescente ao possibilitarlhe o exercício de uma liberdade mais responsável

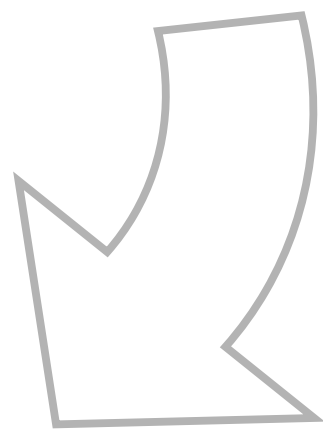

Nos estudos sobre a psicologia da adolescência, existe uma discussão dicotomizada: de um lado, encontram-se aquelas correntes teóricas assentadas nas bases iniciais tais como propostas por Stanley Hall, e que vêem esse momento da vida como natural e universal; uma etapa de crise, vivida de forma indistinta por todos os jovens, independentemente de quais sejam suas inserções culturais. De outro lado, vê-se uma significativa corrente de estudiosos que compreendem a adolescência a partir de seus determinantes históricos e culturais.

No estudo em questão, foi curioso observar que os sujeitos entrevistados, ao abordarem suas experiências de vida, demonstraram concordância com o "pai da psicologia da adolescência" e seus seguidores, confirmando suas idéias. É o caso, por exemplo, de Nilma (3). Essa aluna, ao afirmar que "ser adolescente é uma fase de transição da criança para o adulto, com muita confusão na cabeça da gente, a gente ainda num sabe muita coisa", fala do estado de confusão no qual se encontra imersa, das dificuldades e ambigüidades inerentes a processos transicionais, assim como de seu desconhecimento em relação à vida. Uma visão similar é compartilhada por Breno que vê a adolescência como "uma fase de transição em que você começa a crescer e é uma fase de 
bastante conflito que a gente tem com a gente mesmo e com o mundo, acho que muito conflito mesmo". Também Bianca, para quem a "adolescência é uma fase complicada, que é de descobrimentos [...]", expressa o sentimento de viver um momento complexo e permeado de novidades.

Esses depoimentos validam algumas idéias apresentadas em duas investigações. Salles (1995), após entrevistar vários atores da comunidade escolar de escolas públicas do estado de São Paulo, verificou nos depoimentos a existência de uma tendência à homogeneização da representação social do adolescente e da adolescência, que seriam condizentes com a apresentada pela literatura tradicional. Essas representações, compartilhadas por todos os segmentos analisados, não seriam consistentes quando se tratava de delimitar os personagens em pessoas específicas, ou seja, "no singular e no cotidiano" o núcleo da representação social feita sobre essa faixa etária continuava o mesmo, com adolescentes e adolescência conformando-se de maneira homogeneizada. Também no estudo mais recente de Martins, Trindade e Almeida (2003), observa-se a mesma situação. As autoras ouviram adolescentes de diferentes inserções sociais para saber como eles representavam e davam sentido a esse momento da vida em que se encontravam. Os resultados apontaram que, a despeito de terem sido reveladas formas diferentes de vivenciar a adolescência - como propõe a corrente culturalista - a mesma encontra-se "ancorada na apreensão das concepções mais tradicionais da adolescência" (MARTINS; TRINDADE; ALMEIDA, 2003, p. 567). Reafirma-se, portanto, que ainda persistem nas sociedades ocidentais atuais estereótipos relacionados à adolescência ligados ao que foi proposto por Hall no início do século passado. Especialmente em educação, essa visão é nociva por alimentar preconceitos e impedir o estabelecimento de relações mais amistosas entre educadores e educandos, além de criar dificuldades e entraves ao processo educativo.

Ao se focalizar as representações de liberdade expressas pelos entrevistados ao longo de seus três anos de inserção no contexto estudado, pode-se observar como esse processo dinâmico vai ocorrendo, como vão se processando mudanças no entendimento desses sujeitos o que vem a ser liberdade.

Ao chegar à escola, os adolescentes vivem a liberdade com as cores de um certo deslumbramento e afirmam, a exemplo de Luiz, que "liberdade para mim é fazer o que eu quero, falar o que eu quero". No segundo ano de permanência na escola, já é possível observar uma percepção de que o exercício da liberdade exige responsabilidade e envolve, ainda, um olhar para o outro, como aponta Regina: "acho que liberdade é fazer o que você gosta sem atrapalhar ninguém, sem prejudicar ninguém". No terceiro ano de escola, surge a dimensão do social na vivência da liberdade. De uma 
forma ou de outra, seja como uma alusão à existência das restrições sociais ou mesmo como uma dimensão a ser considerada, os adolescentes se referem a esse aspecto. É como se, nesse momento, - adolescente começasse a se dar conta de que é parte de uma engrenagem social maior, maior do que aquele seu grupinho de amigos, maior do que aqueles grupos sociais que seu olhar consegue captar. O depoimento de Bianca é exemplar nesse sentido: “Liberdade é poder fazer não tudo que você quer, mas o que você quer com responsabilidade. $\mathrm{E}$ acho que a liberdade completa você nunca vai ter também, porque você vive numa sociedade".

Essa limitação implícita na vivência da liberdade é vista pelos adolescentes como necessária, como pode ser observado nas falas de Fernando ("acho que por isso também é importante você se conter, num sair por aí fazendo tudo que tem vontade porque viver em sociedade não é isso, e tem cobranças depois") e de Bianca ("não pode ser uma liberdade desregrada. Eu acho que é muito significativa a questão do limite, porque o mundo está sempre te impondo limites").

Esses relatos nos levam a fazer conexões com uma afirmação de Geymonat (1991). Ao dizer que "carece de fundamento a pretensão de reduzir a liberdade individual a um processo exclusivamente subjetivo", Geymonat (1991, p. 37) nos remete não só à dimensão restritiva da liberdade, mas também e primeiramente à sua dimensão social. Para o autor, a verdadeira liberdade relaciona-se às tentativas dirigidas à superação dos obstáculos que se interpõem no caminho de realização da mesma: é a "luta ininterrupta" que, ao dizer de obstáculos e superação, nos diz também, é óbvio, de limites a serem vencidos, de desafios a serem sobrepujados. Ao nos reportarmos à noção de limite, deve-se, pois, tentar deixar de lado uma certa conotação negativa, que vem sempre associada ao termo e que comporta um caráter de repressão. Cabe especialmente aqui, a idéia apresentada por Outeiral (1994, p. 34), para quem o limite "significa a criação de um espaço protegido dentro do qual o adolescente poderá exercer sua espontaneidade e criatividade sem receio e riscos". Também Gusdorf (1979), ao se indagar sobre a possibilidade de uma liberdade total, afirma que o fato de não existirem antagonismos, obstáculos à liberdade configura-se num caráter negativo e é algo que se pronuncia no vazio. A liberdade comporta uma dimensão social/coletiva que não pode ser negligenciada e a restrição, a resistência que se opõe a uma liberdade total e irrestrita, é parte integrante da condição humana, já que "a existência humana não é uma existência sem condições, mas uma existência em condição, uma existência sob condição" (GUSDORF, 1979, p. 69). Esse caráter de limitação subentendido na liberdade é apontado também por Zavalloni (1968), ao se referir em seu trabalho à síntese da liberdade de escolha e liberdade de ser. 
A maneira como a escola se posiciona em relação à liberdade é, então, um fator de fundamental importância no processo educativo em curso na adolescência, uma vez que, nesse momento "o modo pelo qual se concede a liberdade é definitivo para a conquista da independência e da maturidade" (ABERASTURY; KNOBEL, 1981, p. 16). Nesta perspectiva, para os alunos da escola investigada, a instituição assume o papel de orientadora no aprendizado da responsabilidade e da autonomia, como pode ser visto, por exemplo, nas falas de Kênia e Nilma. Para Kênia, que diz não saber discernir entre o que pode e o que não pode ser feito, "essa liberdade que a gente tem aqui é bom pros alunos amadurecerem, eles mesmos saberem pôr um freio, saberem se pode ou se não pode [...] porque na adolescência é assim mesmo [...] a gente não sabe muito bem o que pode e o que não pode fazer". A mesma visão é compartilhada por Nilma, que afirma que o fato da escola possibilitar ao aluno pensar e tomar decisões por conta própria, "vai abrindo novos horizontes, você vai tendo outra cabeça, você vai tendo que resolver as coisas sozinho e isso é bom pra gente".

Gusdorf (1979, p. 107) vê a adolescência como um "tempo de aprendizado da liberdade" Esse aprendizado, todavia, não se faz desvinculado da responsabilidade, elemento imprescindível na visão de Ricoeur (1999), para quem a liberdade é uma experiência diária apontando sempre na direção de um ser responsável, que, ao agir, expressa sua liberdade em obras e ações dirigidas ao mundo. Essa conexão entre liberdade, responsabilidade e aprendizado de vida é claramente notada pelos adolescentes, como se pode perceber através do relato de Breno, que vê "a liberdade aqui na escola é muito boa se a pessoa tiver responsabilidade; porque não tem ninguém te falando 'agora é horário de fazer isso'. Você é que tem de tomar consciência de fazer o que você acha necessário. Se você não quer estudar, você não estuda. Você tem a liberdade de fazer o que quiser, sem cobrança, e isso acho que ajuda a pessoa a crescer, a ter responsabilidade" (BRENO, 15 anos).

A conexão acima apresentada configura-se como um verdadeiro desafio, não só para adolescentes, mas também para pais e educadores. Ela pressupõe a existência de uma noção já internalizada do que vem a ser responsabilidade, sem a qual não há liberdade, conforme apontado por Gusdorf (1979). É esse mesmo autor que assinala, ainda, um dos papéis centrais a ser exercido não apenas pelos pais, mas também pela escola, que é o de ensinar o jovem a superar as dificuldades encontradas no exercício de sua liberdade. Sabendo de antemão que a trajetória percorrida pelo ser humano nessa direção se caracteriza como um longo e paciente caminho de esforços contínuos e desafios, Gusdorf (1979, p.102) pontua que um dos ensinamentos fundamentais da escola deve ser o da "dificuldade a vencer, do esforço a ultrapassar para conseguir esta criação de si 
por si mesmo, apesar dos obstáculos, que é a finalidade essencial da educação".

A vivência da liberdade na escola, além de contribuir para o amadurecimento, foi significada pelos entrevistados também como uma experiência de aprendizado para o futuro, na medida em que facilita o exercício da autonomia, iniciado pelos adolescentes, como visto anteriormente, no primeiro ano de permanência na escola estudada. Gustavo ilustra bem essa assertiva ao afirmar que "a todo momento essa liberdade aqui está te ensinando, seja ela de forma positiva ou negativa, ela acaba ensinando".

Percebido pelos adolescentes como implícito na vivência da liberdade, esse aprendizado é uma complexa conquista diária, "uma procura do sentido, procura do centro, tomada de consciência da autenticidade pessoal, não sem angústia nem sofrimento" (GUSDORF, 1979, p. 108). Fernando mostra em trechos de seu depoimento uma situação pessoal que é ilustrativa desse aspecto, uma vez que, a partir de um exercício inadequado da liberdade existente no colégio, sobreveio-Ihe como conseqüência uma reprovação e alguns ensinamentos. Dentre eles, o medo de perder conquistas importantes e já estabelecidas e, ainda, a percepção de que o exercício da liberdade é algo difícil e que sempre está relacionado a conseqüências: "o que fez acontecer foi tipo medo, medo de perder o que eu tenho, o que eu conquistei" [...] "e quando você entra aqui você tem que perceber isso direito e se você não percebe, aí vêm as conseqüências depois". "Então, essa liberdade ensina a gente ter essa responsabilidade, ensina a gente a conviver com as outras pessoas [...]" (FERNANDO).

A escola investigada oportuniza ao adolescente viver uma liberdade mais ampliada dentro do seu contexto, valorizando e até mesmo incentivando situações que caminhem nessa direção. Nela, a educação torna-se, segundo Bertan (1994)

\footnotetext{
um processo pessoal em que cada homem vai desabrochando dentro de si as potencialidades e colocandoas em plena atuação, juntamente com outros; neste processo, cada homem vai-se tornando um princípio de iniciativa, isto é, um ser livre, uma pessoa humana, para construir uma sociedade justa e livre" (BERTAN, 1994, p. 65).
}

Essa escola revelada nos depoimentos dos alunos oportuniza práticas ativas e livres que, conseqüentemente, possibilitarão o crescimento do sujeito autônomo. Configura-se assim um sistema educacional baseado na abordagem escolanovista; uma escola que procura se posicionar "como democrática, estimulando o homem criativo, que se relaciona bem com o ambiente e resolve os seus problemas com método" (DALBEN, 1991, p. 63). Essa visão de escola é percebida e valorizada por Júlio, para quem "um colégio democrático é aquele 
que não tenta impor aquilo ali pro aluno [...] então, isso é liberdade. Lá no meu outro colégio tinha disciplinário, aqui não tem nada disso, a gente é mais ouvido aqui".

Destaca-se também a importância da família no processo de formação humana. Esta deve, necessariamente, se unir à escola numa parceria que viabilize desenvolver um projeto em comum que é - de ajudar o ser humano a se tornar sempre e cada vez mais humano (ARROYO, 1999). A referência interna a que os adolescentes se referiram anteriormente pode, então, surgir como um dos resultados dessa parceria imprescindível.

Outra questão relevante aqui se coloca: como o adolescente poderia lidar com essa situação que lhe é nova, de ter que se haver com uma maior liberdade que lhe é concedida pela escola? E como essa instituição poderia ajudá-lo nessa empreitada? De acordo com Gusdorf (1979) a escola e os educadores devem assumir o lugar de observadores atentos e deixar que os jovens vivam a sua liberdade e aprendam com ela, mesmo que para isso eles tenham que percorrer caminhos mais tortuosos, pois muitas vezes, vencer uma dificuldade, ou mesmo o fracasso "tem maior valor formador do que o deixar ir de uma existência canalizada segundo o declive da maior facilidade" (GUSDORF, 1979, p. 109).

Assim é que, na vivência da liberdade na escola dos adolescentes estudados, alguns aspectos foram evidenciados e, juntos, formam uma configuração do que vem a ser essa liberdade tal como ela é experimentada e vivida por esses alunos não só nesse contexto em questão, mas ainda na sua vida extraescolar. Um desses aspectos diz respeito à decisão, elemento de importância significativa no entendimento da liberdade. Ao viverem a sua liberdade, os alunos apontaram que o fazem com base numa decisão que, sabidamente, terá reflexos futuros. Isto está colocado com clareza para Mônica, para quem "a decisão não é só pr'aquela hora, depois vão vir os acontecimentos devidos à decisão que você tomou" e também para Daniel, que afirma que "toda decisão mais importante tem uma influência no futuro".

De fato, quando se pensa em liberdade como um processo que pode levar à auto-realização, vê-se que esse é um projeto contínuo e ininterrupto, onde não está presente apenas a dimensão do presente, mas interpenetram-se e integram-se ativamente o passado representado por toda a experiência acumulada de vida -, o presente e também o futuro. Essa dimensão da ressonância de uma determinada decisão no futuro é percebida por Fernando quando o mesmo afirma que "de todas as decisões você vai tirar sempre uma experiência que vai servir pro caminho que você vai seguir na sua vida toda". Nesse ato de aprender com a decisão, encontra-se a subjetividade como constituinte da ação livre. Pensando que "o fundo do ser é ato" (RICOEUR, 1999) só há liberdade na medida em que 
agimos. Essa ação não é ingênua e nos encaminha para o caminho da transformação subjetiva que, por sua vez, nos levará a realizar mudanças mais concretas, não apenas em nós mesmos, mas também no mundo ao nosso redor. Nesse processo de aprendizagem, a escola pode ser marcante para o adolescente, uma vez que ela se constitui num espaço de aprendizagem da convivência de situações que englobam a dimensão do coletivo, do grupo; ela pode ser um lugar que abra possibilidades aos adolescentes de falarem de si, de seus projetos, sonhos e desejos, trocarem idéias, sentimentos, um lugar, enfim que participe de forma ativa na construção identitária em curso nesse momento da vida humana.

Outra característica importante da decisão sobre a qual se assenta a vivência da liberdade dos adolescentes estudados refere-se à figura do outro. Nos processos decisórios nos quais se encontraram envolvidos, os entrevistados pontuaram que o outro assume um papel de importância e sempre é considerado, tal como é colocado por Rabuske $(1986,2001)$. Para esse autor, o decidir é um processo dialético e que pressupõe um olhar para o outro, parte integrante desse processo. Assim, no momento de uma decisão, não decidimos apenas sobre nós mesmos e nossas vidas, mas decidimos também sobre o outro e daí a importância de se atentar para essa perspectiva, pois Rabuske $(1986,2001)$ admite que

\begin{abstract}
a minha liberdade só adquire um conteúdo adequado na medida em que se abre a uma outra liberdade e na medida em que todos os valores que ela cultiva se tornam meios para um encontro pessoal, uma comunicação das consciências (RABUSKE, 1986, 2001, p. 106).
\end{abstract}

$\mathrm{Na}$ fala dos adolescentes ouvidos, essa preocupação com o outro se sobressai, conforme mostram dois exemplos selecionados: "eu acho que eu penso mais no outro do que em mim mesma" (REGINA). Bianca também afirma que "geralmente, eu penso no outro sim. Penso porque eu acho que a gente não vive sozinha".

A irreflexão e a impulsividade foram detectadas como dois elementos presentes nos processos decisórios encaminhados pelos adolescentes, exemplarmente identificados nas falas de Kênia ("Acho que eu faço muita coisa sem pensar, sabe? Por impulso [...] aquele negócio de ir pensando e colocando em prática, sabe? Não tem essa de ficar refletindo muito não") e Luiz ("Quase nunca a gente pensa antes de decidir, não [...] a gente vai é fazendo as coisas sem pensar mesmo"). Sendo a adolescência um momento onde o jovem vive uma verdadeira crise de temporalidade (ABERASTURY; KNOBEL, 1986), o afobamento, a irreflexão, o imediatismo e a impulsividade são características comuns nesse período. $O$ conceito de tempo cronológico, ilimitado e indefinido para a criança e definido no adulto, na adolescência sofre oscilações entre esses dois pontos e confunde 0 
adolescente, fazendo com que ele também oscile de momentos onde predomina o pensamento imediatista a momentos onde isso não acontece, favorecendo o adiamento infinito de decisões e situações que poderiam ser encaminhadas em tempo mais breve. Atuando com essa noção de limites temporais alterada, oscilante e misturada, o adolescente age, muitas vezes, em busca do prazer imediato, e suas necessidades têm que ser satisfeitas dentro desse tempo imediato.

Gusdorf (1979, p. 85) atenta para o fato de que "o exercício da liberdade se realiza como o encaminhamento pelo qual um homem consegue o complemento de si no decorrer de sua linha de vida". Seria como dizer que o homem encontra-se cotidianamente e sempre à procura de um sentido para sua existência, sem, no entanto, obter alguma certeza sobre o sucesso dessa procura. Essa busca, que encontra na liberdade uma de suas condições fundamentais, é algo que acontece não só no momento presente, mas também no futuro, fazendo com que essa dimensão adquira uma importância essencial: o futuro se faz no presente, se confunde e se mistura com o presente na construção das histórias pessoais.

Aberastury e Knobel $(1980,1986)$ apontam a deslocalização temporal uma das características básicas do processo de adolescer, e perceber e discriminar as dimensões temporais é uma tarefa relevante nesse momento. Ao discernir e definir para si mesmo com mais clareza as noções de passado, presente e futuro, e ao tentar estabelecer um elo de ligação entre elas, o adolescente pode se localizar melhor enquanto sujeito de seus atos. Aberastury e Knobel (1986, p. 40) evidenciam que quando um jovem "pode reconhecer um passado e formular projetos de futuro, com capacidade de espera e elaboração no presente, supera grande parte da problemática da adolescência". Desta forma, na medida em que vai amadurecendo e conseguindo definir para si as noções de passado, presente e futuro, o adolescente consegue manejar melhor o tempo e a tendência é que as dificuldades em lidar com as questões temporais sejam minimizadas. Esse processo pode ser confirmado nesse estudo, onde, apesar dos entrevistados assumirem a citada postura de impulsividade e irreflexão nas suas decisões, observou-se um certo percurso durante os anos de permanência na escola que diz também do amadurecimento desses adolescentes com relação a essa problemática. Desta forma, todos os entrevistados do $1^{\circ}$. ano, sem exceção, afirmaram que não refletem e agem impulsivamente ao tomarem suas decisões. Já no $2^{\circ}$. ano, uma adolescente (REGINA) expressou uma ação excessivamente reflexiva e outro (DANIEL) afirmou que reflete de forma superficial no momento de decisão. No $3^{\circ}$. ano, apesar da reflexão não ocorrer devido às dificuldades e determinações vividas pelo adolescente nos tempos modernos, já acontece a percepção de que o refletir é de fundamental importância num processo decisório. Como exemplo da problemática trazida pelos 
alunos do $3^{\circ}$ ano, é bastante ilustrativo o depoimento de Júlio, que revela a poderosa influência da mídia - especialmente a televisão na sua experiência: "Há uma essência pra mim que a reflexão é essencial, mas infelizmente nós vivemos numa sociedade que está em constantes alterações e nos obriga a tomar atitudes precipitadas". Para Zavaloni (1968), a racionalidade não deve ser o único aspecto a ser considerado num momento de decisão, onde o sujeito deve ainda lançar mão de "[...] capacidades que estão à sua disposição, isto é, empregar o sentido comum, o juízo, a experiência, a capacidade de intuição" (p.322). Ao intuirmos, portanto, não estamos nos deixando levar apenas pelo sentimento, já que o conhecimento intuitivo, apesar de ser menos preciso que o intelectivo, é um conhecimento mais imediato e, em muitos casos, se revela como a melhor escolha possível. A intuição, sentimento que nos possibilita compreender aquilo que ainda não damos conta de explicar racionalmente, em muitos momentos de decisão pode ser nosso único e verdadeiro guia, aquele que "nos conduz para a origem, no sentido pleno da palavra, para a iniciativa criadora" (ZAVALLONI, 1968, p. 322). I sso nos leva a refletir que talvez uma decisão, para ser considerada acertada, ideal de acordo com a situação e as pessoas que se encontram nela envolvidas, não deva necessariamente ser tomada de forma impulsiva e ansiosa, nem tampouco de forma mais lenta e extremamente refletida. Talvez haja a necessidade de se encontrar o "caminho do meio", um equilíbrio que aponte para uma decisão acertada, olhando de forma acolhedora e humana para nós mesmos e para os outros que estão a nosso lado numa determinada situação que exija nosso posicionamento. Talvez tenhamos que percorrer mais vezes o caminho do coração, aquele que nos leva a decidir com base naquilo que sentimos, queremos e intuímos. É preciso que tenhamos sempre em mente que, como seres humanos que somos, estamos sempre sujeitos ao erro em nossas decisões e que, talvez, mais importante do que acertar, seja perceber o erro, sofrer com ele, viver com ele, e tentar transformá-lo em possibilidades de aprendizagem, crescimento e transformação, já que para vivermos nossa liberdade temos também que superar obstáculos que se interpõem no nosso percurso, como observado por Geymonat (1991). Assim, precisamos olhar para nossos erros e vê-los como obstáculos, como desafios que, ao serem superados, nos auxiliam com seu potencial transformador a seguir nossa trajetória de vida de maneira mais suave e mais amadurecida.

\section{Considerações finais}

O processo de educação e formação do ser humano é uma tarefa complexa, um desafio constante e dinâmico para pais e educadores: 
cada momento do desenvolvimento vai requerer dos mesmos novas respostas, novos padrões de conduta e de atendimento às demandas, exigindo-Ihes também criatividade, flexibilidade, escuta e limite. 0 processo de educar é uma arte que consiste, sobretudo, na possibilidade de crescimento mútuo, acompanhando a trajetória que vai desde a total dependência infantil ao processo de autonomia e liberdade exigidas pelo adolescente e conquistadas pelo adulto. Nesta trajetória, a escola pode se colocar como parceira importante e coadjuvante da família na tarefa educativa.

Destaca-se, ainda, que a problemática adolescente não pode ser simplificada a ponto de se atribuir apenas às transformações psíquicas e orgânicas todo o crédito pelas vivências desse momento. $\mathrm{Na}$ visão liberal, de acordo com Bock (2004), ocorre uma naturalização do mundo psíquico e suas decorrências e a ela se contrapõe a visão culturalista na psicologia do adolescente, que busca entender este momento do desenvolvimento humano como integrado e vinculado ao processo de inserção do adolescente na sua cultura e nas relações sociais que desenvolve.

Inserida e sendo parte integrante de uma sociedade em transformação, a escola também vem mudando e se deparando com a necessidade de rediscutir muitas de suas orientações no que se refere ao trato de questões relacionadas ao tema da liberdade. Assim sendo, vive-se nessa instituição um momento de discussão, especialmente no que se refere à educação de crianças e adolescentes: o processo educacional é hoje alvo de questionamentos que se situam em dois pólos, quais sejam, de um lado, a educação tradicional, na qual nós adultos nos formamos, e do outro lado, nitidamente em contraposição, uma educação mais democrática, que propõe uma relação mais prazerosa e provavelmente também mais satisfatória com o conhecimento (OUTEIRAL, 1994).

A escola deve ter ciência de que a maneira como ela se posiciona em relação à liberdade é um fator de fundamental importância no processo educativo de adolescentes. Tal qual a família, esse contexto deve se constituir, para o jovem, num espaço privilegiado de aprendizado de como lidar com a liberdade e, conseqüentemente, com alguns de seus mais importantes elementos, como por exemplo, a responsabilidade, a decisão, a autonomia. Esses e outros aspectos fazem parte da mais relevante tarefa desse momento da vida humana, conforme apontada por Erikson (1972), que é a construção da identidade pessoal, desafio que implica em definir quem a pessoa é, quais serão seus valores, crenças e direções a serem seguidas na vida.

Assim sendo, escola, família e outros contextos onde o adolescente se insere, devem ter em mente que as características de nosso mundo moderno exigem que nos afastemos de todas as formas de violência e/ou autoritarismo no cerceamento do exercício da liberdade 
e, assim, se unir numa parceria que viabilize desenvolver, da melhor forma possível, o seu projeto em comum, que, pensamos, é o de ajudar o ser humano a se tornar sempre e cada vez mais humano.

No encaminhamento desse projeto, pode-se afirmar que, certamente, o modo pelo qual se concede a liberdade na adolescência é definitivo para a conquista da independência e da maturidade (ABERASTURY; KNOBEL, 1981). Ao discutir a questão do limite, ponto central de indagações de pais e educadores de adolescentes, a autora diz que, nessa idade, são mais comuns as exigências por liberdade nas saídas e nos horários, liberdade de defender uma ideologia e a liberdade para viver um amor e um trabalho, sendo que os pais devem ocuparse especialmente da primeira, já que, controlando-se esta, controlam-se também as outras. No entanto, a autora faz também um alerta: se os pais chegaram a esse ponto, é porque anteriormente houve algo mal conduzido na educação como um todo, pois, se houve e há uma relação familiar estruturada em bases como compreensão, amor e confiança, dificilmente esses pais terão dificuldades em lidar com os anseios de liberdade de seus filhos adolescentes. É nesse momento que pais e educadores se encontram diante de dois caminhos, que, obviamente, carregam consigo reflexos e conseqüências diferenciadas. Um primeiro caminho seria o da liberdade excessiva, que assumiria a configuração - perceptível para o adolescente - de um doloroso abandono, o que, sem dúvida, acarretaria em conseqüências significativas para sua trajetória de vida. O segundo caminho, o da restrição, da liberdade com limites, seria aquele que, na grande maioria das vezes, se apresenta para os adultos como o mais difícil de ser percorrido, mas, contudo, seria mais apropriado num processo educacional e, consequentemente, mais favorável ao amadurecimento do jovem. O ato de conter, de oferecer um certo limite às ações adolescentes, não é algo tão fácil quanto parece e requer mais do que simplesmente dizer um não: restringir, conter, oferecer oposição, são ações que exigem escuta, observação, cuidado com o adolescente, afetividade, diálogo, compreensão, firmeza ... Muitas vezes, é mais cômodo permitir sempre, o que evita explicações, enfrentamentos, discussões, diálogos abertos e, quase sempre, embates entre adolescentes e adultos. No entanto, ao trilhar o caminho da permissividade, da liberdade excessiva, pais e educadores devem ter em mente que isso é imediatamente percebido e vivido pelo adolescente como um abandono, o que, nas palavras de Aberastury e Knobel (1981, p. 14), "na realidade o é".

\section{Referências}


ABERASTURY, A.; KNOBEL, M. Adolescência normal - um enfoque psicanalítico. 10.ed. Porto Alegre: Ed. Artes Médicas, 1992 (Original publicado em 1981).

ABERASTURY, A. Adolescência. 5.ed. Porto Alegre: Ed. Artes Médicas, 1988. (Original publicado em 1980).

AMATUZZI, M. M. A. Apontamentos acerca da pesquisa fenomenológica. Estudos de Psicologia, Campinas, v. 13, n. 1, p. 5-10, 1996.

Pesquisa do vivido. In: AMATUZZI, M. M. Por uma psicologia humana. Campinas: Ed. Alínea, 2001a, p. 53-60.

. Pesquisa fenomenológica em Psicologia. In: BRUNS, M.A.T.; HOLANDA, A. F. Psicologia e pesquisa fenomenológica reflexões e perspectivas. São Paulo: Omega Ed., 2001b.

93- $9 \overline{7}$ A subjetividade e sua pesquisa. Memorandum, v. 10, p. <http://www. fafich.ufmg.br/ memorandum/a10/amatuzzi03.htm>. Acesso em: 25 jul. 2011.

Psicologia fenomenológica: uma aproximação teórica humanista. Estudos de Psicologia (Campinas), Campinas, v. 26, n.1, p.93-100, jan./mar. 2009.

ARROYO, M. G. Prefácio. In: DAYRELL, J. (Org.). Múltiplos olhares sobre educação e cultura. Belo Horizonte: Editora UFMG, 1999. p. 7-8.

BERTAN, L. Aspectos da trajetória do ideal de liberdade na educação brasileira (1930-1990). Tese (Doutorado em Educação) - Faculdade de Educação, Universidade Estadual de Campinas, Campinas, 1994, 312p.

BOCK, A.M.B. A perspectiva sócio-histórica de Leontiev e a crítica à naturalização da formação do ser humano: a adolescência em questão. Cadernos Cedes, Campinas, v. 24, n. 62, p. 26-43, 2004. Disponível em:<http://www.cedes.unicamp.br>. Acesso em: 02 jul. 2009.

CHARLOT, B. A mistificação pedagógica: realidades sociais e processos ideológicos na teoria da educação. Rio de Janeiro: Zahar Editores, 1983.

COELHO SOBRINHO, J. Liberdade como pressuposto para a aprendizagem: a integração professor-aluno no aprendizado de artes gráficas. Tese (Doutorado em Comunicação) - Escola de Comunicações e Artes, Universidade de São Paulo, São Paulo, 1986, 88p.

CORREA, M. As ilusões da liberdade: a Escola Nina Rodrigues e a Antropologia no Brasil. Tese (Doutorado em Ciências Sociais) Departamento de Ciências Sociais, Universidade de São Paulo, São Paulo, 1982, 404p. 
DALBEN, A.I.L.F. O adolescente e a escola. In: MAAKAROUN, M.F.; SOUZA, R.P.; CRUZ, A.R. Tratado de adolescência: um estudo multidisciplinar. Rio de Janeiro: Cultura Médica, 1991, 1002p.

DARTIGUES, A. O que é a fenomenologia? Sao Paulo: Centauro, 2003.

ERIKSON, E. H. I dentidade, juventude e crise. Rio de Janeiro: Zahar Editores, 1972.

O ciclo de vida completo. Porto Alegre: Artmed, 1988.

GALLO, S.D.O. Autoridade e a construção da liberdade: 0 paradigma anarquista em educação. 1993, 373p. Tese (Doutorado em Educação) - Faculdade de Educação, Universidade Estadual de Campinas, Campinas, 1993.

GEYMONAT, L. La libertad. Barcelona: Editorial Crítica, 1991.

GIOVANETTI, J.P. O sagrado e a experiência religiosa na psicoterapia. In: MASSIMI, M.; MAFHOUD, M. (Orgs). Diante do mistério psicologia e senso religioso. São Paulo: Ed.Loyola, 1999, p.87-96.

A vivência religiosa no mundo (pós) moderno. Belo Horizonte: UFMG/FAFICH, 13 p., 2000(mimeo).

GOMES, A.L.A.A. Controle-liberdade: apontamentos para um estudo. Dissertação (Mestrado em Educação) - Faculdade de Educação, Universidade Federal do Rio Grande do Norte, Natal, 1994, $87 p$.

GUSDORF, G. I mpasses e progressos da liberdade. São Paulo: Ed. Convívio, 1979.

HUSSERL, E. A crise da humanidade européia e a filosofia. 2. Ed. Porto Alegre: EDIPUCRS, 1897/2002.

MACIEL, J.C. Franz Clemens Brentano e a Psicologia. In: BRUNS, M.A.T.; HOLANDA, A.F. (Orgs). Psicologia e pesquisa fenomenológica, reflexões e perspectivas. São Paulo: Ômega Editora, 2001, p.34-45.

MAFHOUD, M. Encomendação das almas: mistério e mundo da vida em uma tradicional comunidade mineira. In: MASSIMI, M.; MAFHOUD, M. (Orgs). Diante do mistério - Psicologia e senso religioso. São Paulo: Ed. Loyola, 1999, p.57-68.

MARQUES, E.R. Sobre o conceito de liberdade. Mini-colóquio sobre - conceito de liberdade. Material didático do colóquio. Faculdade de Filosofia e Ciências Humanas da UFMG, 16 e 17/12/2000.

MARTINS, P.O.; TRINDADE, Z.A.; ALMEIDA, A.M.O. O ter e o ser: representações sociais da adolescência entre adolescentes de inserção urbana e rural. Psicologia: Reflexão e Crítica, v.16, n.3, p. 555-568, 2003.

MUUSS, R.E.H. Teorias da adolescência. Belo Horizonte: Interlivros, 1976.

OUTEIRAL, J.O. Adolescer: estudos sobre adolescência. Rio de Janeiro: Revinter, 2008. 
RABUSKE, E.A. Antropologia filosófica - um estudo sistemático. Petrópolis: Ed. Vozes, 2001.

RENAUT, A. O indivíduo-reflexão acerca da filosofia do sujeito. Rio de Janeiro: Difel, 1998.

RICOEUR, P. Liberté. In: Encyclopédie Philosophique Universelle. Paris: Presses Universitaires de France, 1999, 4v, p.622-651.

SALLES, L.M.F. A representação social do adolescente e da adolescência: um estudo em escolas públicas. Cadernos de Pesquisa, São Paulo, n.94, p.25-33, ago.1995.

WEIZ, T.; SANCHEZ, A. As ideias, concepções e teorias que sustentam a prática de qualquer professor, mesmo quando ele não tem consciência delas. In: WEIZ, T.; SANCHEZ, A (Orgs). O diálogo entre o ensino e a aprendizagem. São Paulo: Ática, 2002, p. 1721.

WESTERA, D.A.; BENNETT, L.R. Population-focused research: a broad-based survey of teens' attitudes, beliefs and behaviors. Canadá: Memorial University of Newfoundland, School of Nursing St.J ohn's, 1994.

WOJ TYLA, K. Persona e atto. Vaticano: Ed. Vaticana, 1982.

ZAVALLONI, R. A liberdade pessoal - Psicologia da conduta humana. Petrópolis: Ed. Vozes, 1968.

\section{Endereço para correspondência}

Rita de Cássia Vieira

Faculdade de Educação - DECAE, Av. Antonio Carlos 6627 - Campus da Pampulha, Belo Horizonte, MG, Brasil

Endereço eletrônico: rita.vieira@yahoo.com.br

Recebido em: 21/02/2011

Reformulado em: 20/07/2011

Aceito para publicação em: 02/08/2011

Acompanhamento do processo editorial: Ana Maria Lopez Calvo de Feijoo

\footnotetext{
NOTAS

* Mestre em Psicologia (UFMG), Doutora em Educação (UFMG), Psicóloga, Cocoordenadora do Laboratório de Psicologia e Educação Helena Antipoff da Faculdade de Faculdade de Educação da UFMG (Laped/FaE-UFMG)

1 Artigo baseado na Dissertação de Mestrado da autora, defendida junto ao Programa de Pós-Graduação em Psicologia da Faculdade de Filosofia e Ciências Humanas da Universidade Federal de Minas Gerais, sob a orientação do Prof. Dr. J osé Paulo Giovanetti, a quem agradeço profundamente.

2 John Dewey, filósofo, psicólogo e pedagogo norte-americano, foi o precursor nos E.U.A. dos pressupostos democráticos na educação, em contraposição ao clima autoritário tradicional. Para Dewey, a escola tradicional, ao impor normas de "cima para baixo" e opor-se ao cultivo da individualidade, representava uma grande restrição à liberdade. Foi o mais importante pensador e mentor da educação democrática norte-americana e seu pragmatismo (o ponto-chave de sua proposta era a ação, o concreto, e buscava sempre orientar seus alunos para o alcance de
} 
objetivos práticos bem definidos) tornou-se a contribuição central dos E.U.A. para a filosofia ocidental (BERTAN, 1994).

${ }^{3}$ Todos os entrevistados tiveram seus nomes alterados. 